\title{
R Programı ve Microsoft Excel Kullanılarak İkili Karşılaştırma Yöntemi Uygulaması
}

\section{Pair-Wise Comparasion Method Application Via R Project and Microsoft Excel}

\author{
Cem Oktay GÜZELLER* Mehmet Taha ESER** Gökhan AKSU***
}

\begin{abstract}
Öz
$\mathrm{Bu}$ araştırmada üniversite öğrencilerinin okul dışında gerçekleştirdikleri boş zaman aktivitelerinin değerlendirilmesine yönelik araştırmacılar tarafından "Boş Zamanı Değerlendirmeye İlişkin İkili Karşılaştırmalar Ölçeği” geliştirilmiştir. Ölçme aracından elde edilen sonuçların Thurstone tarafindan geliştirilen karşılaştırmalı yargılar kanununa göre R programı ile analiz etmek ve ilgili bulguları frekans yöntemiyle excel ortamında elle gerçekleştirilmiş yöntemin analiz sonuçları ile karşılaştırmak amaçlanmıştır. $\mathrm{Bu}$ amaç kapsamında öncelikle ikili karşılaştırmalar yönteminin gerçekleştirilebilmesi için ölçme aracı geliştirilmiştir. Araç, 8x8 kare matris formatında oluşturulmuş ve uzman görüşleri ile öğrencilerden alınan dönütler sonucunda ölçme aracına son hali verilmiştir. Veriler 2015 - 2016 Eğitim Yılı Güz Yarıyılında bir fakültede öğrenim gören 306 öğrenciden elde edilmiştir. Elde edilen bulgulara göre hem R programı ile gerçekleştirilen hem de excel kullanılarak gerçekleştirilen hesaplamaların birbirine çok benzer olduğu görülmüştür. Hem R programı hem de excel ile gerçekleştirilen ölçekleme işlemi sonucunda öğrencilerin boş zamanlarında en fazla arkadaşlarıyla vakit geçirdikleri ve sosyal aktiviteleri tercih ettikleri, kitap okumayı ve bilgisayar başında vakit geçirmeyi ise en son tercih ettikleri belirlenmiştir.
\end{abstract}

Anahtar Kelimeler: Ölçekleme, İkili karşılaştırma, R Programı, Boş zaman etkinliği

\begin{abstract}
"Pairwise Comparison For Spending Leisure Time" was developed in this study by the researches for the evaluation of leisure time activities of university students out of the university. This study indented to analyze the results obtained by the measurement instruments through the Program $\mathrm{R}$ according to the comparative judgement law developed by Thurstone. Within the scope of this purpose, a measurement scale was developed to realize first the pairwise comparisons method. The tool was created in the format of $8 \times 8$ square matrix and finalized according to the expert views and the feedbacks from the students. The data was obtained from 306 students studying at a faculty in the spring term of the academic year 2015-2016. According to the findings, the calculations by both the Program R and the Microsoft Excel were found to be very similar. After the scaling by both the Program R and the Microsoft Excel, it was determined that the students spent most of their leisure time with friends and preferred to have social activities while reading books and spending time at the computer were the least preferred activities.
\end{abstract}

Key Words: Scaling, Pairwise comparison method, R Programming, Leisure activity

\section{GíRIŞ}

İkili karşılaştırmalar yöntemi, psikolojide kullanılan ölçekleme tekniklerinden bir tanesidir (Turgut ve Baykul, 1992). İkili karşılaştırma yönteminde ölçek yapısı için tasarım ve prensip Thurstone'un çalışmasına (1927) dayanmaktadır. Thurstone, tutumların ölçülebileceğini ileri sürerken, tek seferde iki uyaran arasında basit karşılaştırmalara dayalı bir grup uyaranın ölçeklenmesi için kullanılabilecek olan bir işlem ve model geliştirmiştir. Thurstone sürecin formülüzasyonunu'Karşılaştırmalı Yargılar

\footnotetext{
*Doç. Dr., Hacettepe Üniversitesi, Eğitim Fakültesi, Ankara-Türkiye, e-posta: cguzeller@ gmail.com

**Uzman, Türkiye Belediyeler Birliği, Ankara-Türkiye, e-posta: tahaeser@gmail.com

***Öğr. Gör., Adnan Menderes Üniversitesi, Aydın MYO, Aydın-Türkiye, e-posta: gokhanaksu1983@ hotmail.com
}

Ĕgitimde ve Psikolojide Ölçme ve Değerlendirme Dergisi, Cilt 7, Sayı 1, Yaz 2016, 96-108.

Journal of Measurement and Evaluation in Education and Psychology, Vol. 7, Issue 1, Summer 2016, 96-108. 
Kanunu" olarak adlandırmıştır. Örneğin, bir kişinin çeşitli ağırlıklarda beş cismin algılanan ağırlıklarını ölçmek istediğini varsayalım. Bireyler, cisimlerin ağırlıklarını ikili olarak karşılaştırtarak veriler elde edilebilir ve algılanan ağırlıkların ölçek değerlerini tahmin etmek için karşılaştırmalı bir şekilde karara varabilirler. Bu, cisimlerin fiziksel ağırlığına algısal olarak denktir. Ölçek yerleri her uyaranın lehine muhakemelerin oranlarından çıkarılır (Heldsinger ve Humphry, 2010).Thurstone’un ikili karşılaştırma modeli Rasch modelinin bir öncülüdür (Andrich, 1978a).

Thurstone tipi ölçekleme söz konusu olduğunda birkaç yöntem göze çarpmaktadır. İkili karşılaştırma yöntemi bunlardan bir tanesidir. İkili karşılaştırma yönteminde de diğer yöntemlerde olduğu gibi yargıcı kararlarına gerek duyulmaktadır.Ölçekleme işlemini gerçekleştirirken, araştırmacıların geliştirdiği "Rekreasyon Etkinliklerinin Değerlendirilmesine İlişkin İkili Karşılaştırmalar Ölçeğì" nden elde edilen sonuçlar kullanılmıştır.

Boş zaman, bireyin hem şahs1, hem de diğer bireyleri göz önünde bulundurarak bütün güçlüklerden uzaklaştığı, kendi öz iradesini kullanarak seçtiği bir faaliyetle uğraştığı, bireyin özgür bir şekilde kullanabildiği, yaratıcı ve manevi değerlerin kaynağı olarak görülen zamandır (Godbey ve Stanley, 1976; Hacıoğlu ve diğ., 2003). Boş zamanı değerlendirme (recreation) kavramı, bireylerin boş zamanlarında gerçekleştirdiği etkinlikleri merkeze alan bir kavramdır. Boş zamanları değerlendirme sadece bireyler için bir ihtiyaç, verimli bir hayata sahip olma şekli ve manevi anlamda rahatlama sağlayan bir yol değildir, aynı zamanda bireyler boş zamanlarını değerlendirerek kendini ifade etme ve kişiliğini geliştirme fırsatına sahip olur (Karaküçük, 1999; Terzioğlu ve Yazıcı, 2003; Gökmen ve diğerleri, 1985).

Zamanın zengin ve etkili bir şekilde değerlendirilmesi önemli bir konudur. Yanlış ve verimsiz zaman yönetimi sonucu meydana gelen sıkıntılar bireyi ve tüm toplumu olumsuz bir şekilde etkilemektedir (Jennen ve Uhlebuck, 2004). Ülkemizde boş zaman genellikle iyi bir şekilde değerlendirilememekte okuma düzeyinin düşük olması vb. sebepler düşünüldüğünde özellikle de gençlere yeterince iyi alışkanlıklar kazandırılamadığı gözlemlenmektedir (Karaküçük, 1995; Karaküçük ve Başaran, 2000). Bireylerin farklı yaşam tarzları ve alışkanlıkları göz önünde bulundurulduğunda değişik boş zaman değerlendirme şekillerinin olduğu görülmektedir. Teknolojinin ilerlemesi ile birlikte kitle iletişim araçları bireyler için ortak boş zaman değerlendirme aktivitelerinin oluşmasında ve küresel bir ortam oluşmasında büyük rol oynamıştır (Pekince, 2012; Aydın,2000).

Rekreasyon değerlendirme tercihlerinin birçok araştırmaya konu olması (Kim, 2008; Yin ve diğ., 2009; Trottier ve diğ., 2002; Terzioğlu ve Yazıc1, 2003) ve dolayısıyla boş zamanları değerlendirmeye ilişkin bir ölçek geliştirirken konu ile ilgili geniş bir literatürü inceleyebilme imkanı, ilgili konunun hala popülerliğini koruması, literatür incelendiğinde araştırmacılar tarafından boş zamanları değerlendirme tercihlerine yönelik kapsamlı bir ikili karşılaştırma ölçeğine rastlanmamış olması sonucunda ilgili ölçek oluşturulmuş ve araştırma kapsamında kullanılmıştır.

Araştırma kapsamında geliştirilen ölçekten elde edilen ikili karşılaştırma sonuçları kullanılarak frekans matrisi ile oranlar matrisi oluşturulmuş ve bu matrisler kullanılarak excel ve $\mathrm{R}$ programları vasıtasıyla Thurstone V. Hal ve III. Hal İkili Karşılaştırma Uygulamaları gerçekleştirilmiştir.

\section{Araştırmanın Amacı}

Alanyazında ikili karşılaştırmalar yöntemine ilişkin çalışmalar oldukça yaygındır (Anıl ve Güler, 2006; Nartgün, 2006; Acar Güvendir ve Özer Özkan, 2013; Öztürk ve diğ., 2011; Özer ve Acar, 2011; Altun ve Gelbal, 2014). Ancak, yapılan bu çalışmalar incelendiğinde, tüm çalışmaların excel ortamında formüllerin elle işlenerek frekans temelli bir şekilde gerçekleştirildiği görülmektedir. $\mathrm{Bu}$ durum, hem uzun hem zaman alıcı hem de hataya daha açık bir hesaplama ortamının oluşmasına sebebiyet vermektedir. Ancak $\mathrm{R}$ gibi, içerisinde ikili karşışşırmalara dair istatistiksel hesaplamaların gerçekleştirilebileceği bir paket tarafından desteklenen açık kaynak kodlu yazılımların bu amaçla kullanılması hatayı minimum seviyeye indirmektedir. Bir analizi birçok değer için tekrar etme, veriyi işleme ve programlama ile benzer problemlere hızlı çözüm bulma vb. özellikler göz önünde bulundurulduğunda excel yerine R programını kullanmanın daha avantajlı 
olduğu göze çarpmaktadır (Crawley, 2007; Heidberger ve Neuwirth, 2009). İkili karşılaştırmalar yöntemine dair Thurstone V. Hal Çalışması R programı ile gerçekleştirilebilmektedir. Excel ile gerçekleştirilen ikili karşılaştırmalar yönteminde excel yerine $\mathrm{R}$ programı kullanılarak ikili karşılaştırmaya dair ölçeklemenin daha kolay daha rahat ve daha sorunsuz bir şekilde gerçekleştirilmesi göz önünde bulundurulduğunda, konu ile ilgili gelecekte gerçekleştirilecek olan çalışmalarda $\mathrm{R}$ programının kullanım sıklığının artacağı düşünülmektedir. Bu kapsamda çalışma oldukça önemlidir.

\section{YÖNTEM}

Çalışma fakültelerde görevli öğretim üyeleri ve öğrencilerle yapılan görüşmeler sonucunda belirlenmiş boş zaman aktivitelerinden frekans değeri en yüksek sekiz farklı etkinliğin öğrenci yargılarına göre kendi içinde ikili karşılaştırma esasına dayanmaktadır. Thurstone (1927) tarafından geliştirilen karşılaştırmalı yargılar kanunu temel alınarak yapılan analizlerde öğrenciler her bir aktiviteyi ikili karşılaştırarak hangi aktiviteyi daha çekici buluyorlarsa ilgili matriste üstün olan aktiviteye 1 , diğerine 0 puan vererek kodlama yapmışlardır. $\mathrm{Bu}$ bilgiler kullanılarak ikili karşılaştırma sonucunda aktivitelerin ölçek değerleri elde edilmiştir. Bu araştırmanın amacı, farklı programlarla gerçekleştirilen analiz sonuçlarını karşılaştırarak, analiz sonuçları arasındaki benzer ve farklı yönleri ortaya çıkarmak olduğundan çalışmanın yöntemi nicel araştırma yöntemlerinden karşılaştırmalı çalışmalar modeli altında değerlendirilmelidir (Mills, Bunt ve Brujin, 2006).

\section{Çalışma Grubu}

Araştırmanın çalışma grubunu Aydın ilinde yer alan bir üniversitenin farklı bölümlerinde öğrenim gören öğrenciler oluşturmaktadır. Uygulama 2015-2016 eğitim-öğretim yılı güz yarıyılında yapılmıştır. Çalışma gönüllülük esasına dayalı olarak, uygulamaya katılmak isteyen öğrenciler ile gerçekleştirilmiştir. Tabakalı örnekleme yöntemiyle belirlenen 350 öğrenciye uygulama formu dağıtılmıştır. Dağıtılan formlardan 44 tanesinin eksik ve hatalı doldurulması sebebiyle değerlendirmeye 306 form alınmıştır.

\section{Veri Toplama Araçları}

Öğrencilerin belirlenen 8 farklı boş zaman aktivitesinden ikili karşılaştırma yaparak hangisini daha fazla tercih ettiklerini belirlemek amaciyla $8 \times 8$ türünde kare matris oluşturulmuştur. Matrisin alt ve üst köşegen matrisinde benzer karşılaştırmaları iki defa yapmamak amacıyla alt köşegen matris kullanılarak karşılaştırma yapmaları istenmiştir (Ek-1). Geliştirilen ölçme aracında yer alacak aktiviteleri belirlemek amacıyla sayısal ve sözel ağırlıklı bölümlerde görev yapan öğretim elemanları ve öğretim üyelerinden oluşan 10 kişilik bir ekipten uzman görüşü alınmıştır. Uzman görüşleri ve sonrasında öğrencilerle yapılan görüşmeler doğrultusunda frekans değeri en yüksek 8 aktivite (spor yapmak, kitap okumak, sosyal aktivite, arkadaşlarla vakit geçirmek, bilgisayar karşısında vakit geçirmek, telefon uygulamaları ile vakit geçirmek, tv seyretmek, uyumak) matris üzerine yerleştirilerek uygulama formuna son şekli verilmiştir. Matrisin $8 \times 8$ türünde kare matris olması, alt üçgen üzerinde işaretleme yapılması ve toplam gözenek sayısının 32 olması sebebiyle her hücreye en az 5 veri girmesi $(32 * 5=160)$ amacıyla katılımcı sayısı yüksek tutulmuştur.

\section{Verilerin Analizi}

Verilerin analizinde psikolojik özelliklerin ölçeklenmesinde yaygın olarak kullanılan tekniklerinden ikili karşılaştırma yöntemiyle ölçekleme tekniğinden yararlanılmıştır (Thurstone, 1927; Turgut ve Baykul, 1992). Thurstone (1927) tarafından geliştirilen karşılaştırmalı yargılar kanunu temel alınarak yapılan analizlerde öğrenciler her bir aktiviteyi ikili karşılaştırarak hangi aktiviteyi daha çok tercih ediyorlarsa bunu ilgili matriste üstün olan aktivite 1 , diğerine 0 puan vererek kodlama yapmışlardır. 
$\mathrm{Bu}$ bilgiler kullanılarak ikili karşılaştırma yapılan aktivitelerin ölçek değerleri elde edilmiştir. Araştırmada elde edilen verilerin analizine R programı için V. Hal, Excel için V. ve III. Hal Yöntemiyle ölçekleme gerçekleştirilerek sonuçlar tutarlılık açısından incelenmiştir. Ölçeklemede ikili karşılaştırmada kullanılan temel formüllerden yararlanılmıştır (Turgut ve Baykul, 1992). Öğrencilerin vermiş oldukları yanıtlarda çelişkili üçlüler olup olmadığı ki kare değerleri ile kontrol edilerek yanıtlarında çelişkili üçlü bulunan öğrencilere ait anket sonuçları analiz kapsamına alınmamıştır.

R programlama dili, ilk defa Yeni Zelanda’ da yer alan Aucland Üniversitesi İstatistik Bölümü’ nden Ross Ihaka ve Robert Gentleman tarafından oluşturulmuştur. Sonraları dünyanın farklı bölgelerindeki araştırmacılardan meydana gelen bir grup R programlama dilinin gelişimine yardımcı olmuştur. Bu gruba, 1997 yılında "R Core Team" ismi verilmiş ve R programlama dili bu grupta yer alan araştırmacıların da katkılarıyla günümüzdeki halini almıştır.

R programı, profesyonel veya ticari desteğe tabi, kapalı kutu yazılımlardan oluşan bir program değildir."R" dili için geliştirilmiş, dile yeni özellikler kazandıran birçok paket mevcuttur. Bu paketlerin çok büyük bir kısmı çevrim içi ortamda "CRAN" adı verilen bir "merkez" üzerinde bulunmaktadır. Araştırma kapsamında gerçekleştirilen ikili karşılaştırma yöntemi ile ölçekleme analizini içeren algoritmalar, "Psych" paketi içerisinde yer almaktadır.

Psych paketi, psikometri alanında kullanılan ve istatistiksel hesaplamaları içeren bir pakettir. İçerisinde güvenirliğe, geçerliğe, klasik test teorisine, madde tepki kuramına ve ölçeklemeye ilişkin analizlerin gerçekleştirilebileceği küçük paketler yer almaktadır.

R programı kullanılarak ikili karşılaştırmalara dair hesaplama yapmak için, öncelikle "Psych" paketi R sistemine yüklenmelidir. Psych paketi içerisinde, ikili karşılaştırmalar yöntemi için hazırlanmış "vegetables" isimli örnek bir veri seti yer almaktadır.Bu veri seti, ilgili analiz konusunda deneyim sahibi olmak için kullanılabilir.R programı üzerinde ikili karşılaştırmalar yöntemi ile analiz gerçekleştirmek için http://personality-project.org/r/html/thurstone.html uzantıli linkten gereken kısa ve öz bilgi elde edilebilir. İlgili paket install.packages("psych") komutu ile sisteme yüklendikten sonra paketin library(psych) komutu ile program üzerinde çalışmaya hazır hale gelmesi sağlanmalıdır. Program kullanılarak ilgili analizin gerçekleştirilmesi için daha sonra çalışma için kullanılacak olan veri seti program üzerinde çalıştırılmalı ve ikili karşılaştırma yöntemi ile ölçekleme analizi gerçekleştirilmelidir.

\section{BULGULAR}

\section{R Programı Kullanılarak III. Hal Ölçekleme Çalışması}

R programı kullanılarak V. Hal Ölçekleme Çalışması gerçekleştirmek için oranlar matrisini kullanmak yeterli olmaktadır. Oranlar matrisi oluşturulurken, excel ile gerçekleştirilen hesaplamada köşegen matrisini oluşturan hücreler boş bırakılırken, $\mathrm{R}$ programı için oluşturulması gereken oranlar matrisinde köşegen matrisini oluşturan hücrelere 0,5 değeri yazılmalıdır. Tablo 1' de konu ile ilgili $R$ programı için hazırlanmış oranlar matrisi görülmektedir.

Tablo 1. R Programı için Oranlar Matrisi

\begin{tabular}{ccccccccc}
\hline & $\mathrm{A}$ & $\mathrm{B}$ & $\mathrm{C}$ & $\mathrm{D}$ & $\mathrm{E}$ & $\mathrm{F}$ & $\mathrm{G}$ & $\mathrm{H}$ \\
$\mathrm{A}$ & 0,500000 & 0,349673 & 0,705882 & 0,797386 & 0,375817 & 0,549020 & 0,496732 & 0,669935 \\
B & 0,650327 & 0,500000 & 0,712418 & 0,735294 & 0,522876 & 0,594771 & 0,624183 & 0,764706 \\
C & 0,294118 & 0,287582 & 0,500000 & 0,496732 & 0,192810 & 0,264706 & 0,261438 & 0,555556 \\
D & 0,202614 & 0,264706 & 0,503268 & 0,500000 & 0,111111 & 0,166667 & 0,163399 & 0,457516 \\
E & 0,624183 & 0,477124 & 0,807190 & 0,888889 & 0,500000 & 0,539216 & 0,480392 & 0,728758 \\
F & 0,450980 & 0,405229 & 0,735294 & 0,833333 & 0,460784 & 0,500000 & 0,290850 & 0,594771 \\
G & 0,503268 & 0,375817 & 0,738562 & 0,836601 & 0,519608 & 0,709150 & 0,500000 & 0,705882 \\
H & 0,330065 & 0,235294 & 0,444444 & 0,542484 & 0,271242 & 0,405229 & 0,294118 & 0,500000 \\
\hline
\end{tabular}


Oranlar matrisi oluşturulduktan sonra, matris $\mathrm{R}$ programı üzerinde çalıştırılmalıdır. Matris $\mathrm{R}$ programı üzerinde çalıştırıldıktan sonra, "thurstone(Dataset)" komutu ile analiz sonuçlandırılır. Parantez içerisinde yer alan "Dataset" yerine araştırmada kullanılacak olan veri setinin ismi yazılmalıdır. Araştırma için ilgili veri setine "Dataset" ismi verilmiştir. Şekil 1' de veri setinin program üzerinde görüntülenmiş hali yer almaktadır.

\begin{tabular}{|c|c|c|c|c|c|c|c|c|}
\hline \multicolumn{3}{|c|}{ R packages available $*$} & \multicolumn{6}{|l|}{ Dataset $*$} \\
\hline \multicolumn{9}{|c|}{ 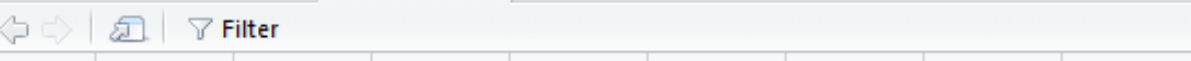 } \\
\hline & A & B & C & D & $\mathbf{E}$ & $\mathbf{F}$ & G & $\mathbf{H}$ \\
\hline A & 0.500000 & 0.349673 & 0.705882 & 0.797386 & 0.375817 & 0.549020 & 0.496732 & 0.669935 \\
\hline B & 0.650327 & 0.500000 & 0.712418 & 0.735294 & 0.522876 & 0.594771 & 0.624183 & 0.764706 \\
\hline C & 0.294118 & 0.287582 & 0.500000 & 0.496732 & 0.192810 & 0.264706 & 0.261438 & 0.555556 \\
\hline D & 0.202614 & 0.264706 & 0.503268 & 0.500000 & 0.111111 & 0.166667 & 0.163399 & 0.457516 \\
\hline E & 0.624183 & 0.477124 & 0.807190 & 0.888889 & 0.500000 & 0.539216 & 0.480392 & 0.728758 \\
\hline $\mathbf{F}$ & 0.450980 & 0.405229 & 0.735294 & 0.833333 & 0.460784 & 0.500000 & 0.290850 & 0.594771 \\
\hline G & 0.503268 & 0.375817 & 0.738562 & 0.836601 & 0.519608 & 0.709150 & 0.500000 & 0.705882 \\
\hline H & 0.330065 & 0.235294 & 0.444444 & 0.542484 & 0.271242 & 0.405229 & 0.294118 & 0.500000 \\
\hline
\end{tabular}

Şekil 1. Veri Setinin R Programındaki Görünümü

Veri seti programa okutulduktan sonra;install packages("psych")komutu ile sisteme yüklenen ve daha sonra library(psych) komutu ile program üzerinde çalışmaya hazır hale getirilen "psych", paketi içerisinde yer alan "thurstone" komutu ile analizin gerçekleştirilmesi için Thurstone (Dataset) komutu program ekranına girilir ve 'Enter"' tuşuna basılarak analiz çıktısı elde edilir.

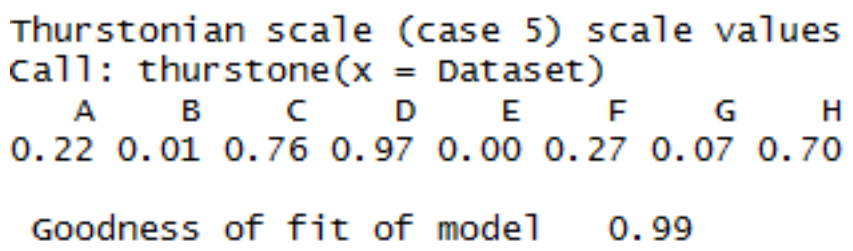

Şekil 2.R Programına İlişkin V. Hal Ölçekleme Çalışması Çıktısı

Şekil 2' de, R programında gerçekleştirilen Thurstone V. Hal ölçekleme sonuçları görülmektedir. V. Hal denklemi yardımıyla elde edilen ölçek değerleri incelendiğinde sıralama anlamında en çok tercih edilen aktivitelerin sırasıyla Arkadaşlarla vakit geçirme (D) ile Sosyal Aktiviteler (C) ve Uyku (H) olduğu, en az tercih edilen aktivitelerin ise sırasıyla Bilgisayar karşısında vakit geçirme (E), Kitap okuma (B) ve TV Seyretme (G) olduğu görülmektedir.

\section{Excel Kullanılarak III. Hal Ölçekleme Çalışmast}

Çalışmanın bu bölümünde, ikili karşılaştırmalar sonucu elde edilen veri setinin Excel kullanılarak izlenen III. Hal Ölçekleme süreci ve bulgular konusunda bilgi verilmiştir. Bunun için ilk olarak, öğrencilerin ikili karşılaştırma sonucu verdikleri tepkilere ilişkin frekans değerleri belirlenmiş ve sonuçlar Tablo 2'de verilmiştir. 
Tablo 2. Boş Zamanları Değerlendirme Yöntemlerine İlişkin Frekans Matrisi (F)

\begin{tabular}{ccccccccc}
\hline & $\mathbf{A}$ & $\mathbf{B}$ & $\mathbf{C}$ & $\mathbf{D}$ & $\mathbf{E}$ & $\mathbf{F}$ & $\mathbf{G}$ & $\mathbf{H}$ \\
\hline $\mathbf{A}$ & & 107 & 216 & 244 & 115 & 168 & 152 & 205 \\
$\mathbf{B}$ & 199 & & 218 & 225 & 160 & 182 & 191 & 234 \\
$\mathbf{C}$ & 90 & 88 & & 152 & 59 & 81 & 80 & 170 \\
$\mathbf{D}$ & 62 & 81 & 154 & & 34 & 51 & 50 & 140 \\
$\mathbf{E}$ & 191 & 146 & 247 & 272 & & 165 & 147 & 223 \\
$\mathbf{F}$ & 138 & 124 & 225 & 255 & 141 & & 89 & 182 \\
$\mathbf{G}$ & 154 & 115 & 226 & 256 & 159 & 217 & & 216 \\
$\mathbf{H}$ & 101 & 72 & 136 & 166 & 83 & 124 & 90 & \\
\hline
\end{tabular}

Tablo 2'de verilen frekans matrisi öğrencilerin tercih ettikleri aktiviteleri tercih edilme sıklıklarına göre oluşturulmuştur. Tabloda spor yapmak (A), kitap okumak (B), sosyal aktivite (C), arkadaşlarla vakit geçirme (D), bilgisayar karşısında vakit geçirme $(\mathrm{E})$, telefon uygulamaları ile vakit geçirmek $(\mathrm{F})$, TV seyretmek $(\mathrm{G})$ ve uyumak $(\mathrm{H})$ olmak üzere toplam 8 boş zaman aktivitesi ikili karşılaştırılmıştır. Tabloda görüldüğü üzere B aktivitesi ile A aktivitesi karşılaştırıldığında çalışma grubunda bulunan 306 öğrencinin 199'u B aktivitesini tercih etmelerine rağmen 107'si A aktivitesini tercih etmişlerdir. Frekans matrisi tüm aktivitelerin ikili karşılaştırılmasına dayanan sonuçlardan oluşturulmuştur. Frekans matrisinde esas köşegen üzerindeki hücrelerde her aktivitenin kendisiyle karşılaştırma yapıldığı anlamına geldiğinden bu hücreler boş bırakılmıştır. Frekans matrisi oluşturulduktan sonra her bir hücrede yer alan değerlerin toplam öğrenci sayıs1 olan 306'ya bölünmesiyle oranlar matrisi elde edilmiştir. Oranlar matrisine ilişkin sonuçlar Tablo 3’te verilmiştir.

Tablo 3. Boş Zamanları Değerlendirme Yöntemlerine Illişkin Oranlar Matrisi (P)

\begin{tabular}{llllllllll}
\hline & $\mathbf{A}$ & $\mathbf{B}$ & $\mathbf{C}$ & $\mathbf{D}$ & $\mathbf{E}$ & $\mathbf{F}$ & $\mathbf{G}$ & $\mathbf{H}$ \\
\hline $\mathbf{A}$ & &, 35 &, 71 &, 80 &, 36 &, 55 &, 50 &, 67 \\
$\mathbf{B}$ &, 65 & &, 71 &, 74 &, 52 &, 59 &, 62 &, 76 \\
$\mathbf{C}$ &, 29 &, 28 & &, 50 &, 19 &, 26 &, 26 &, 56 \\
$\mathbf{D}$ &, 20 &, 26 &, 50 & &, 11 &, 17 &, 16 &, 46 \\
$\mathbf{E}$ &, 62 &, 47 &, 81 &, 89 & &, 54 &, 48 &, 73 \\
$\mathbf{F}$ &, 45 &, 41 &, 74 &, 83 &, 46 & &, 29 &, 59 \\
$\mathbf{G}$ &, 50 &, 38 &, 74 &, 84 &, 52 &, 71 & &, 71 \\
$\mathbf{H}$ &, 33 &, 24 &, 44 &, 54 &, 27 &, 41 &, 29 & \\
\hline
\end{tabular}

Tablo 3'te verilen matriste esas köşegene simetrik olan değerlerin toplamının 1 olduğu görülmektedir. Oranlar matrisindeki hücrelerde yer alan değerlere karşıllk gelen birim normal değerler (z değerleri) elde edilmiştir. Z Matrisinde sütun toplamları bulunduktan sonra bu değerler sekiz farklı etkinlik olduğundan 8'e bölünerek $S_{j}$ değerleri elde edilmiştir. Eksenin başlangıç noktasını sıfır yapmak amacıyla her bir $S_{j}$ değerine bu değerin mutlak değeri olan .376 eklenerek her bir aktivitenin ölçek değeri belirlenmiştir. Her bir aktiviteye ilişkin ölçek değerleri Şekil 3’te gösterilmiştir.

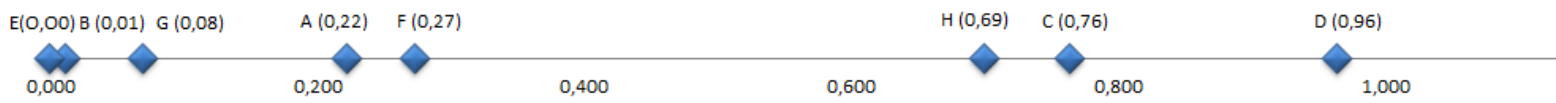

Şekil 3.V. Hal Yöntemiyle Ölçekleme 
Şekil 2 ve şekil 3 karşılaştırmalı olarak incelendiğinde, R programı ile elde edilen V. Hal yöntemine ilişkin sonuçlar ile Excel kullanılarak elde edilen V. Hal yöntemine ilişkin sonuçların neredeyse tamamıyla benzerlik gösterdiği görülmektedir.

V. Hal Yöntemiyle gerçekleştirilen ölçekleme işlemi sonucunda ortalama hata değeri 0,329 ve hesaplanan $\chi^{2}$ değerinin 21 serbestlik derecesinde $\% 95$ güven derecesinde beklenen değerden büyük olması sebebiyle ve verilerin uyum ölçütlerini karşılamaması nedeniyle psikometrik yapı da göz önünde bulundurularak III. Hal denklemi yardımıyla ölçekleme yapılmasına karar verilmiştir. İki yöntem arasındaki fark ise ölçekleme yapılırken V. Hal denkleminde ayırt etme yargılarının varyansı eşit kabul edilirken III. Hal denklemi ayırt etme yargıları varyansını eşit kabul etmemekte ve her bir yargı için tek tek varyansları hesaplaması sebebiyle kullanılmaktadır (Turgut ve Baykul, 1992). Çalışmada III. Hal denklemiyle elde edilen ölçekleme sonuçları Şekil 4’te gösterilmiştir.

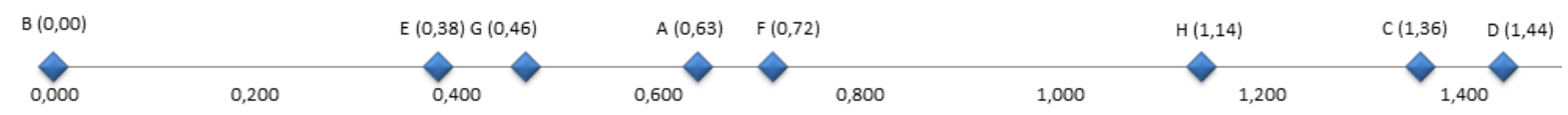

Şekil 4. III. Hal Yöntemiyle Ölçekleme

Hem Excel ve R ile gerçekleştirilen V. Hal hem de Excel ile gerçekleştirilen III. Hal yöntemi yardımıyla yapılan ölçekleme çalışmaları sonucunda boş zaman aktivitelerinin sıralarında büyük bir değişiklik olmadığı görülmüştür. Çalışmada V. Hal denklemi yardımıyla elde edilen ve III. Hal denklemi yardımıyla elde edilen ölçek değerleri karşılaştırıldığında sıralama anlamında en çok tercih edilen aktivite Arkadaşlarla vakit geçirme (D) ile Sosyal Aktiviteler (C) ve Uyku (H) olduğu görülmektedir. Ancak en az tercih edilen aktivitelere bakıldığında V. hal denkleminde sirasıyla Bilgisayar karşısında vakit geçirme (E), Kitap okuma (B) ve TV Seyretme (G) olmasına karşın III. hal denkleminde sırasıyla Kitap okuma (B), Bilgisayar karşısında vakit geçirme (E) ve TV Seyretme (G) olduğu görülmektedir. Hem V. hal hem de III. Hal yönteminde tüm aktivitelerin ölçek üzerindeki yerleri aynı olmasına karşın sadece en az tercih edilen Kitap okuma ve TV Seyretme aktivitelerinin yerlerinin değiştiği görülmektedir. Ölçek değeri aralıklarına bakıldığında III. Hal denklemi yardımıyla elde edilen ölçek değeri aralıklarının V. Hal denklemine göre biraz daha genişlediği görülmüştür. Bu sonuç Aksu ve Doğan (2015) tarafından yapılan çalışmanın sonuçlarıyla benzerlik göstermektedir. Bunun yanında III. Hal denklemi yardımıyla en az tercih edilen aktivitelerin daha iyi ayrılabildiği belirlenmiştir. Bu sonuçlara göre öğrenci görüşlerine göre en çok tercih edilenden en az tercih edilene doğru siralama değerleri Tablo 4'de hem V. Hal hem de III. Hal Yöntemiyle elde edilen ölçek değerleri için gösterilmiştir.

Tablo 4.V. ve III. Hal Yöntemiyle Elde Edilen Değerlerin Karşıllaştırılması

\begin{tabular}{|c|c|c|c|c|}
\hline & \multicolumn{2}{|l|}{ V. HAL YÖNTEMİ } & \multicolumn{2}{|l|}{ III. HAL YÖNTEMI } \\
\hline Sira & & Ölçek & Altivito & Ölçek \\
\hline No & Akuvile & Değeri & AKuVIIL & Değeri \\
\hline 1 & Arkadaşlar (D) & 0,96 & Arkadaşlar (D) & 1,44 \\
\hline 2 & Sosyal aktivite (C) & 0,76 & Sosyal aktivite (C) & 1,36 \\
\hline 3 & Uyku (H) & 0,69 & Uyku (H) & 1,14 \\
\hline 4 & Telefon uygulamaları (F) & 0,27 & Telefon uygulamaları (F) & 0,72 \\
\hline 5 & Spor yapmak (A) & 0,22 & Spor yapmak (A) & 0,63 \\
\hline 6 & TV seyretmek $(\mathrm{G})$ & 0,06 & TV seyretmek $(\mathrm{G})$ & 0,46 \\
\hline 7 & Kitap okumak (B) & 0,01 & Bilgisayar (E) & 0,38 \\
\hline 8 & Bilgisayar $(\mathrm{E})$ & 0,00 & Kitap okumak (B) & 0,00 \\
\hline
\end{tabular}


Tablo 4 incelendiğinde en çok tercih edilen ilk altı aktivitenin sıralamada yerleri aynı kalmasına karşın kitap okuma ve bilgisayar başında vakit geçirme aktivitelerinin sıra değerlerinde değişiklik olduğu görülmektedir.

\section{SONUÇLAR ve TARTIŞMA}

Bu çalışmada üniversite öğrencilerinin boş zamanlarını değerlendirmeleri bakımından en çok tercih ettikleri 8 farklı boş zaman aktivitesinin farklı programlarla gerçekleştirilen analiz sonuçlarını karşılaştırarak, analiz sonuçları arasındaki benzer ve farklı yönleri ortaya çıkarmak amaçlanmıştır. Yargıcı kararlarına dayalı ölçekleme tekniklerinden biri olan ikili karşılaştırmalar yöntemiyle öğrencilerin en çok tercih ettiklerini düşündükleri yöntemleri karşılaştırmaları istenmiştir (Kan, 2008).

Elde edilen sonuçlara göre, Thurstone V. Hal Ölçeklemesinin R programı ile gerçekleştirilen analiz sonuçlarının, Excel ile gerçekleştirilen analiz sonuçları ile çok benzer olduğu görülmektedir. Excel ile gerçekleştirilen V. Hal Ölçekleme Hesaplamalarının el yordamı ile gerçekleştirilmesi, fazla zaman alması ve hataya açık olması sebebi ile bu hesaplamalar R programı ile daha kısa sürede ve analiz sürecinin içerisine bireysel hata karışma ihtimali en düşük düzeyde olacak şekilde gerçekleştirilebilmektedir. R programının açık kaynak kodlu olması, ücretsiz bir yazılım olması, Excel ile oluşturulan veri setlerinin program içerisine aktarılabilmesi gibi özellikleri de ikili karşılaştırmalar ölçekleme yöntemi konusunda $\mathrm{R}$ programının rahatlıkla excel yerine kullanılabilmesi için geçerli sebepler olarak düşünülebilir.

Yargıcı tepkilerine dayalı ölçekleme yöntemleri düşünüldüğ̈̈nde, R programı ile sadece Thurstone V. Hal Ölçekleme Yöntemi gerçekleştirilebilmektedir. Gelecekte gerçekleştirilecek olan araştırmalarda, R programının açık kaynak kod özelliği göz önünde bulundurularak Thurstone III. Hal Ölçekleme yöntemine dair kodlar yazılabilir ve sonuç olarak bu ölçekleme yöntemi R programı ile gerçekleştirilebilir ve excel ile elden edilen III. Hale ilişkin ölçek değerleri ile R programı ile elde edilen III. Hale ilişkin ölçek değerleri elde edilebilir.

R programı ile gerçekleştirilen Thurstone V. Hal Ölçekleme işlemi sonucunda ölçek değerlerinin yanında goodness of fit indice (uyum iyiliği indeksi) elde edilmektedir. Uyum iyiliği indeksinin elde edilmesi, kullandığımız yöntemin yanlışlanabilir olduğunu göstermekte, yani uyum iyiliği indeksinin alacağı değere göre ilgili çalışmaya devam edilip edilmeyeceği konusunda bilgi sahibi olunmaktadır.

Elde edilen sonuçlar, üniversite öğrencilerinin rekreasyon değerlendirme tercihleri açısından incelendiğinde ilgili sekiz etkinlik en çok tercih edilenden en az tercih edilene arkadaşlarla vakit geçirme, sosyal aktiviteler, uyku, tv seyretme, kitap okuma ve bilgisayar karşısında vakit çevirme şeklinde sıralanmıştır. Üniversite öğrencilerinin kitap okuma alışkanlığı açısından yoksun olduklarını göstermektedir. Üniversite öğrencilerinin okuma alışkanlığı elde edebilmesi için üniversite kütüphaneleri öğrenciler için çekici bir hale getirilmeli ve öğrencilerin de tercihleri göz önünde bulundurarak çeşitli kitapların sayısı arttırılmalıdır. Üniversitelerde yer alan faaliyetler öğrencileri okumaya özendirecek şekilde düzenlenmelidir. Öğrencilerin ilgi ve ihtiyaçları göz önünde bulundurulduğunda, okuma ortamları tasarlanırken öğrencilerin ilgi ve ihtiyaçları da göz önünde bulundurulmalıdır. Sekiz etkinliğin sıralamadaki yeri bir bütün olarak düşünüldüğünde; üniversite öğrencilerinin yoksun bir rekreatif etkinlik tercihi anlayışının olduğu söylenebilir.

\section{KAYNAKÇA}

Acar Güvendir, M. ve Özer Özkan, Y. (2013). İki Ölçekleme Yönteminin Karşılaştırılması: İkili karşılaştırma ve siralama yargiları [A Comparison of Two scaling Methods: Pair Wise Comparison and Rank-Order Judgments Scaling]. Eğitim Bilimleri Araştırmaları Dergisi - Journal of Educational Sciences Research. 3 (1), 105-119. [Online]: http:// http://ebad-jesr.com/ adresinden 11 Ocak 2016 tarihinde indirilmiştir. 
Aksu, G. ve Doğan, N. (2015).Öğretim Yöntem ve Tekniklerinin Öğrenci Görüşlerine Göre İkili Karşılaştırma Yöntemiyle Ölçeklenmesi. Eğitimde ve Psikolojide Ölçme ve Değerlendirme Dergisi, 6 (2), 194-206

Andrich, D. (1978a). A rating formulation for ordered response categories. Psychometrika, 43, 561573.

Altun, A. ve Gelbal S. (2014).Öğretmenlerinin Kullandıkları Ölçme ve Değerlendirme Yöntem veya Araçlarının İkili Karşılaştırma Yöntemiyle Belirlenmesi. Eğitimde ve Psikolojide Ölçme ve Değerlendirme Dergisi, 2 (2), 200-209.

Anıl, D. ve Güler, N. (2006). İkili karşılaştırma Yöntemi ile Ölçekleme Çalışmasına Bir Örnek. Hacettepe Üniversitesi Ĕ̈itim Fakültesi Dergisi. 30, 30-36.

Aydın, M. (2000). Kurumlar Sosyolojisi. Ankara: Vadi Yayınları.

Baykul, Y. ve Turgut, M. F. (1992) Ölçekleme Teknikleri.Ankara: Meteksan Anonim Şirketi

Becker, R. A., Chambers, J. M. and Wilks, A. R. (1988). The New S Language. Wadsworth \& Brooks/Cole.

Crawley, M. J. (2007). The R book. Chichester, West Sussex, England: Wiley.

Demirel, Ö. (2011). Öğretme Sanatı. Ankara: Pegem Akademi.

Ergani, K. (2010). İlkögretim 4. ve 5. Sinıf Sosyal Bilgiler Dersi Öğretim Yöntem ve Teknikleri İle Materyal Kullanımına İlişkin Öğretmen Görüşleri. Yayınlanmış Yüksek Lisans Tezi, Dumlupınar Üniversitesi Sosyal Bilimler Enstitüsü, İlköğretim Anabilim Dalı, Kütahya.

Gökçe, F. (1994). Eğitimde Denetimin Amaç ve İlkeleri, Hacettepe Üniversitesi Ĕ̌itim Fakültesi Dergisi,10,73-78.

Godbey, G., Stanley, P. (1976). Leisure Studies and Services: An Overview. Pennsylvania: W.B. Saundersco.

Gönen, S., ve Kocakaya, S. (2006). Fizik Öğretmenlerinin Hizmet İçi Eğitimler Üzerine Görüşlerinin Değerlendirilmesi. Pamukkale Üniversitesi Eğitim Fakültesi Dergisi, 19, 37-44,

Hacıoğlu, N., Gökdeniz, A., Dinç, Y. (2003). Boş zaman ve Rekreasyon Yönetimi. Ankara: Detay Yayınları.

Heidberger, R.M., Neuwirth, E. (2009). R Through Excel: A Spreadsheet interface for Statistics, Data Analysis, and Graphics. Springer, New York.

Heldsinger, S., Humphry, S., (2010). Using the method of pairwise comparison to obtain reliable teacher assessments. The Australian Educational Researcher, 37(2).

Hesapcıoğlu, M. (2011). Öğretim Illke ve Yöntemleri. Ankara: Nobel Yayınları.

İşman, A. ve Eskicumalı, A.(1999). Eğitimde Planlama ve Değerlendirme. Adapazarı: DeğişimYayınları.

Jennen, C., Uhlebuck, G. (2004). Exercise and life satisfaction: Fitness complimentary strategies in the prevention and rehabilitation of ilness. Evidence-based Complimentary and Alternative Medicine, 1(2), $147-165$

Jungst, S.,Licklider, B. \&Wiersema, J. (2003). Providingsupport forfacultywhowishtoshiftto a learningcenteredparadigm in theirhighereducation classrooms. The Journal of Scholarshipof Teachingand Learning, 3, 69-81.

Ishiyama, J.T.,McClure, M., H. ve Amico, J. (1999) Critical thinkingdispositionandlocus of control as predictors of evaluations of teachingstrategies.CollegeStudentJournal, 33 (2), 10-44.

Kan, A. (2008). Psikolojik Değişkenleri Ölçmek İçin Kullanılan Ölçekleme Yaklaşımları ÜzerineBirKarşılaştırma.Ĕ̈itimde Kuram ve Uygulama, 4 (1), 2-18.

Kayabaşı, Ş. ve Erdoğan, Y. A. (2002). Öğretimi Planlama ve Değerlendirme.Ankara: Anı Yayınevi.

Kahyaoğlu, M ve Yangın, S. (2007). İlköğretim Öğretmen Adaylarının Mesleki Öz Yeterliklerine İlişkin Görüşleri. Kastamonu Ĕgitim Dergisi, 15, 83-105.

Karaağaçlı, M. (2005), Öğretimde Yöntemler ve Yaklaşımlar. Ankara: Pelikan Yayıncılık.

Karaküçük S., Başaran Z. (2000). Stresle Başa Çıkmada Rekreasyon Faktörü. Gazi Beden Eğitimi ve Spor Bilimleri Dergisi. Ankara.

Karaküçük S. (1995). Rekreasyon (Boş Zamanları Değerlendirme). Seren Matbaacılık. Ankara.

Karaküçük, S. (1999).Rekreasyon Boş Zamanları Değerlendirme. Ankara: Bağırgan Yayımevi.

Kılıç, C. (2010). Illköğretim Okullarında (Devlet-Özel) ve Dershanelerde Görev Yapan Fen ve Teknoloji Öğretmenlerinin Kullandıkları Öğretim Yöntem ve Teknikleriyle İlgili Öğrenci Görüşleri, Yüksek Lisans Tezi,Gazi Üniversitesi Eğitim Bilimleri Enstitüsü, İlköğretim Bölümü Fen Bilgisi Öğretmenliği Bilim Dalı, Ankara.

Kim, B. B. (2008). Research update: Perceiving leisure. Parks \& Recreation, 43(5), 24-27

Küçükahmet, L. (1983). Öğretim İlke ve Yöntemleri. Ankara ÜniversitesiEğitim Bilimleri Fakültesi Yayınları No: 124.

Küçükahmet, L. (1995). Öğretim Illke ve Yöntemleri. Ankara: Gazi Büro Kitabevi.

Larson R. W. \& Richards, M. H. (1991). Daily companionship in late childhood and early adolescence: Changing developmental contexts. Child Development, 62, 284-300 
Marbach-Ad, G.,Seal, O.\&Sokolove, P. (2001). Student attitudesand recommendations on active learning. Journal of CollegeScienceTeaching, JO, 434-438.

Mills, M., Bunt, G. G. ve Brujin, J. (2006).Comparative research persistent problems and promising solutions.International Sociology, 21 (5), 619-631.

Murphy, B. C., Eisenberg, N., Fabes, R. A., Shepard, S. ve Guthrie, I. K. (1999). Consistency and change in children's emotionality and regulation: A longitudinal study. Merrill-Palmer Quarterly: Journal of Developmental Psychology. 45, 413-444.

Nartgün, Z, (2006). Öğretmenlik Meslek Bilgisi Derslerinin Önem Düzeyinin İkili Karşılaştırmalarla Ölçeklenmesi.A.İ.B.Ü. Ĕ̈itim Fakültesi Dergisi, 6 (2), 161- 176.

Önen, F., Mertoğlu, H., Saka, M. ve Gürdal, A. (2009).Hizmet içi Eğitimin Öğretmenlerin Öğretim Yöntem ve Tekniklerine ilişkin Bilgilerine Etkisi: ÖPYEP Örneği.Ahi Evran Üniversitesi Ĕ̆itim Fakültesi Dergisi, 10 (3), 9-23.

Önen, F., Saka, M., Erdem, A., Uzal, G. ve Gürdal, A., (2008). Hizmet İçi Eğitime Katılan Fen Bilgisi Öğretmenlerinin ÖğretimTekniklerine İlişkin Bilgilerindeki Değişimin Tespiti: Tekirdağ Örneği.KEFAD, 9 (1), 45-57

Özden, Y. (2000).Öğrenme ve Öğretmen.Pegem A Yayıncılık, Ankara.

Özer, Y. ve Acar, M. (2011). Öğretmenlik Mesleği Genel Yeterlikleri Üzerine İkili Karşılaştırma Yöntemiyle Bir Ölçekleme Çalışması. Çukurova Üniversitesi Eğitim Fakültesi Dergisi. 3 (40), 89-101.

Öztürk, N., Özdemir, S. ve Gelbal, S. (2011).İki farklı ölçekleme yaklaşımından elde edilen ölçek değerleri tutarlılığının incelenmesi. 20. Ulusal Eğitim Bilimleri Kurultayı. 8-10 Eylül 2011.Burdur.

Peker, M. ve Mirasyedioğlu, Ş. (2003). Lise 2. Sınıf Öğrencilerinin Matematik Dersine Yönelik Tutumları ve Başarıları Arasındaki İlişki.Pamukkale Eğitim Fakültesi Dergisi, 2 (14), 157-166.

Revelle, W. (2009) An Introduction to Psychometric Theory with Applications in R. Springer.

Saban, A. (2004). Öğrenme Öğretmen Süreci Yeni Teori ve Yaklaşımlar.Nobel Yayınevi, Ankara.

Tan, Ş., Kayabaş1, Y ve Erdoğan, A. (2002). Öğretimi Planlama ve Değerlendirme (3. Baskl), Ankara: Anı Yayınc1lik.

Taşpınar, M. (2005). Kuramdan Uygulamaya Öğretim Yöntemleri.Ankara: Nobel Yayınevi.

TDK (2014). Türk Dil Kurumu Genel Türkçe Sözlük. Erişim Tarihi: 25.05.2014.

Terzioğlu, A. \& Yazıcı, M. (2003).Üniversite Öğrencilerinin Boş Zamanlarını Değerlendirme Anlayış ve Alışkanlıkları (Atatürk Üniversitesi örneği). Erzincan Eğitim Fakültesi Dergisi. 5(2), 1-31.

Thurstone, L. L. (1927). The method of paired comparisonsfor social values. Journal of Abnormal and Social Psychology, 33, 529-54.

Thurstone, L. L. (1928). The Measurement of Values. Chicago, USA: The University of Chicago Press.

Thurstone, L. L. (1959). The method of paired comparisonsfor social values. Journal of Abnormal and Social Psychology, 21, 384-400.

Tohumcu, T. (2004). Adıyaman Merkez İlköğretim Okulları 5. Sinıf Öğrencilerinin Matematik Dersindeki Başarıları ile Bu Öğrencilerin Sınıf Öğretmenlerinin Öğretim Yöntemleri Arasındaki İlişkinin Incelenmesi, Yayınlanmış Yüksek Lisans Tezi, İnönü Üniversitesi Sosyal Bilimler Enstitüsü, Malatya.

Trottier, A. N., Brown, G. T., Hobson, S. J. G. \& Miller, W. (2002). Reliability and validity of the Leisure Satisfaction Scale (LSS-short form) and adolescent leisure interest profile (ALIP). Occupational Therapy International, 9(2), 131-144.

Turgut, M. F. ve Baykul, Y. (1992). Ölçekleme Teknikleri. Ankara: ÖSYM Yayınları.

Uysal, A. (2010). Sinıf Ögretmenlerinin 2009 Hayat Bilgisi Ögretim Programında Belirtilen Strateji, Yöntem ve Teknikleri Uygulamadaki Yeterlilik Düzeylerinin Belirlenmesi.Yayınlanmış Yüksek Lisans Tezi, Ankara Üniversitesi Eğitim Bilimleri Enstitüsü, Ankara.

Vural, B. (2006). Ĕgitim-Öğretimde Planlama-Ölçme ve Stratejiler. İstanbul: Hayat Yayıncılık.

Yeşilyurt, E. (2013). Öğretmenlerin Öğretim Yöntemlerini Kullanma Amaçları ve Karşılaştıkları Sorunlar.Atatürk Üniversitesi Sosyal Bilimler Enstitüsü Dergisi, 17 (1), 163-188.

Yıldız, S. (2008). Özel Ĕ̈itim Sınıflarında Çalışan Sınıf Öğretmenlerinin Matematik Öğretiminde Kullanılan Öğretim Yöntemlerine İlişkin Görüşlerin Değerlendirilmesi. Yayınlanmış Yüksek Lisans Tezi, Selçuk Üniversitesi Sosyal Bilimler Enstitüsü, Konya

Yin, Z., Katims, D. S. ve Zapata, J. T. (1999). Participation in leisure activities and involvement in delinquency by mexican american adolescents. Hispanic Journal of Behavioral Sciences, 21(2), 170185. 


\section{EXTENDED ABSTRACT}

\section{Introduction}

The design and principle for the scale structure in the paired comparison method is based on the study of Thurstone $(1927,1959)$. Thurstone suggested that attitudes could be measured and he developed a process and model which could be used for the scaling of a group of stimuli based on simple comparisons between two stimuli at one time. Thurstone named the formulation of the process as "Law of Comparative Judgement". Several methods stand out with respect to Thurstonetype scaling. The paired comparison method is one of them. Decisions of judges are required in the paired comparison method like in the other methods. This study attempted to determine the level of preference of the leisure time activities of the university students. Leisure time refers to the time which is regarded as the source of creative and moral values where an individual moves away from all difficulties considering both himself/herself and other individuals and deals with an activity chosen by own will (Godbey and Stanley, 1976; Hacioğlu, Gökdeniz and Dinç 2003). The concept of recreation centres around the activities carried out by persons in their leisure times. Making use of leisure time is not only a need of individuals, a method of having an efficient life and a way of moral relief but also an opportunity for individuals for expressing themselves and developing their personalities through recreation (Karaküçük, 1999; Terzioğlu and Yazıc1, 2003; Gökmen and diğerleri 1985). It is essential to make use of time through an enhanced and effective way. The problems which occurs through wrong and inefficient time management have a negative effect on the individual and society as whole (Jennen and Uhlebuck, 2004). Leisure time is not used generally well in our country and it is observed that young people don't have good habits due to various reasons like low level of reading etc. Considering the different life styles and habits of individuals, we see that they have various ways of spending leisure time. Following the technological advancements, mass communication played great role in the creation of common leisure time activities and a common global environment for individuals (Pekince, 2012; Aydın, 2000). The R Project was used in the study in order to compare the scaling results of the paired comparison to the results obtained through the formula suggested by Thurstone.

\section{Method}

The analyses were based on the law of comparative judgements developed by Thurstone (1927) and students conducted paired comparison for each activity and coded the attractive activities by giving 1 point to the favourable activity and 0 point to the other. They obtained the scale values of the activities after paired comparison using this information. The study group of this research consists of the faculty students studying at different departments of a university in the Aydin province. The application was conducted in the fall semester of the academic year 2015-2016. The study was conducted with the students based on voluntariness. Application forms were distributed to 350 students who were determined by the strafied sampling method. 306 forms were taken for evaluation while 44 forms were incomplete and wrongly completed. In order to determine the activities to be included in the measurement tool, expert opinions were taken from a team of 10 people consisting of lecturers and instructors who work in the numerical and verbal departments. The application form was finalized by placing on the matrix the 8 activities with the highest frequency value in line with the expert views and talks made with students. Paired comparison scaling technique was used in the data analysis which is one of the most common techniques in scaling the psychological qualities (Thurstone, 1927; Turgut and Baykul, 1992).The analyses were based on the law of comparative judgements developed by Thurstone (1927) and students conducted paired comparison for each activity and coded the attractive activities by giving 1 point to the favourable activity and 0 point to the other. For the analysis of the obtained data, the results were examined for consistency by conducting scaling through the case V. method for the R project and through the case V. and III. methods for the Excel. 


\section{Results and Discussion}

Ratios matrix was used to conduct the case III scaling study by using the R project. When we look at the case $\mathrm{V}$ scaling results, the most preferred activities were respectively spending time with friends (D), social activities $(\mathrm{C})$ and sleeping $(\mathrm{H})$ while the least preferred activities were spending time on computer (E), reading books (B) and watching TV $(\mathrm{G})$. In addition, as a result of the case III scaling process followed by the Excel program, the most preferred activities were respectively spending time with friends (D), social activities $(\mathrm{C})$ and sleeping $(\mathrm{H})$ while the least preferred activities were spending time on computer (E), reading books (B) and watching TV (G). These results obtained by the $\mathrm{R}$ project are similar to almost all of the results obtained by the Excel program. As a result of the scaling works done by both the case V method and case III method, no big difference was seen in the order of leisure time activities. When the scale values of obtained by the case V equation and case III equation were compared, the most preferred activities were respectively spending time with friends (D), social activities (C) and sleeping $(\mathrm{H})$. However the least preferred activities in the case $\mathrm{V}$ equation were respectively spending time on computer (E), reading books (B) and watching TV (G) while these activities in the case III equation were respectively reading books (B), spending time on computer (E) and watching TV (G). According to the obtained results, the analysis results done by the $\mathrm{R}$ project were very similar with the analysis results obtained with the Excel program. The case III scaling calculations with the excel program are done gropingly, take more time and are open to error, therefore, these calculations can be done with the $\mathrm{R}$ project in a shorter time and with the smallest possibility to have individual errors. When the obtained results are examined with respect to the recreation evaluation preferences of the university students, the eight activities rank from the most preferred to the least preferred as spending time with friends, social activities, sleeping, watching TV, reading books and spending time on computer. It is determined that the university students don't have reading habits. University libraries should be made attractive for students and number of books should be increased in line with the student preferences so that the university students may gain reading habits. The activities within universities should be arranged to encourage students for reading. Reading environments should be designed taking the interests and needs of students into consideration. Considering the eight activities as a whole in the ranking, it can be said that the university students had a poor understanding of recreational activity preference. 
Güzeller, C. O., Eser, T., Aksu, G. / R Programı ve Microsoft Excel Kullanılarak İkili Karşılaştırma Yöntemi Uygulaması

\section{EK-1. Veri Toplama Aracı}

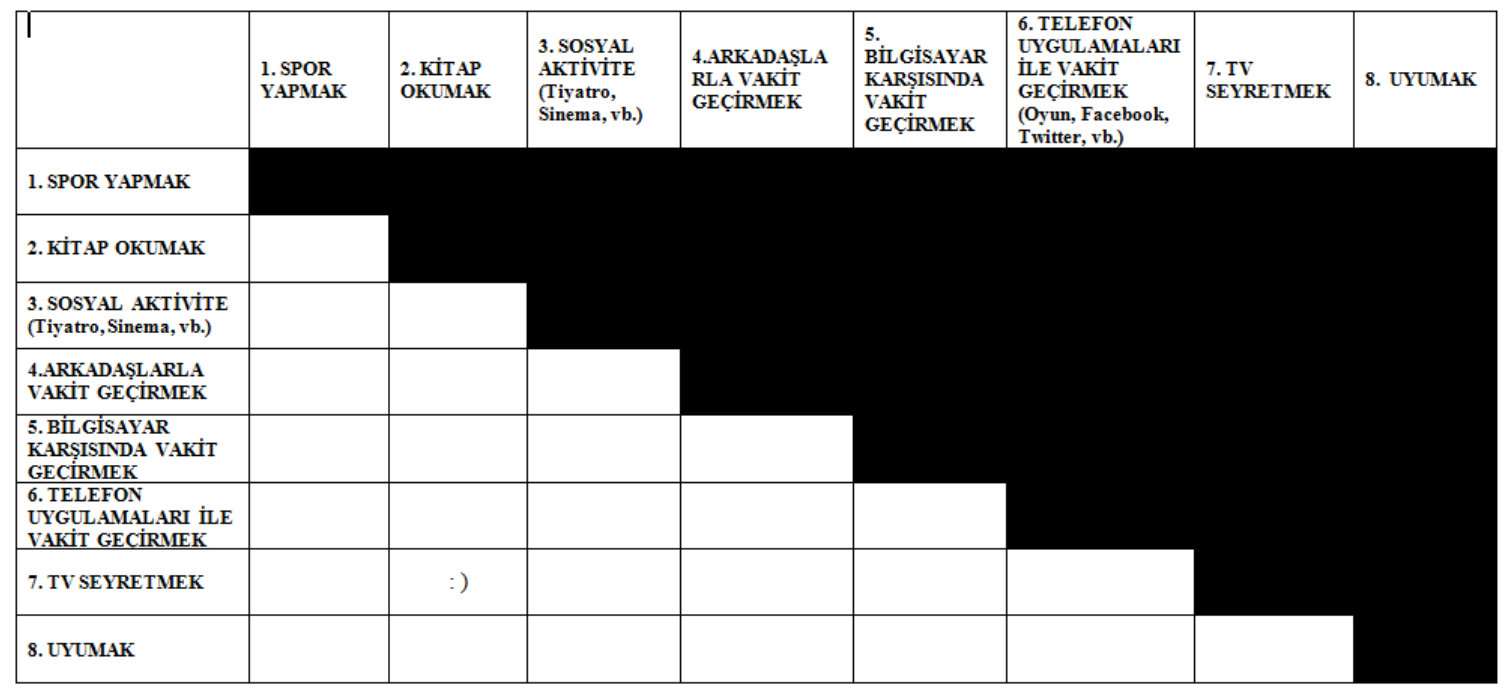

NOT: Yukarıdaki matriste yatayda (satrr) ve dikeyde (sütun) boş zaman etkinlikleri bulunmaktadır. Sizden istenilen her bir etkinliği ikili karșilaștırma yapmanızdır. Daha açik bir ifadeyle satır ve sütunda yer alan iki etkinlikten birini tercih etmeniz gerekseydi hangisini seçerdiniz? Ömeğin 7. Satırdaki TV Seyretmek ile 2. sütundaki Kitap Okumak etkinliğini karşılaştıran bir öğrenci iki seçeneğin kesiştiği noktaya (tabloda gülücük olan hücre) eğer yataydaki etkinliği (TV Seyretmek) daha çok tercih ediyorsa "TV"; eğer dikeydeki etkinliği (Kitap Okumak) daha çok tercih ediyor ise "Kitap" yazması gerekmektedir. Benzer şekilde boş olan tüm hücreler için aynı işlemi yapmanız gerekmektedir. Ayrıca siyah alanlara işaretleme yapmayınız. 